Eur J Clin Chem Clin Biochem

1995; 33:285-288

(c) 1995 Walter de Gruyter \& Co.

Berlin $\cdot$ New York

\title{
Evaluation of a First-Line Spectrophotometric Screening Test for Increased Faecal Porphyrin Concentration
}

\author{
By Floris M. J. Zuijderhoudt ${ }^{1}$, Jenneke Dorresteijn-de Bok ${ }^{1}$ and Kornelis te Velde ${ }^{2}$ \\ 1 Department of Clinical Chemistry \\ 2 Department of Medicine \\ Deventer Ziekenhuis, Deventer, The Netherlands
}

(Received December 19, 1994/February 2, 1995)

Summary: We compared a spectrophotometric screening test measuring faecal porphyrin concentration with an HPLC method. There was a good overall correlation between both methods although some scatter was observed. ROC plot analysis of the screening test leads to a cut-off value of $35 \mathrm{nmol}$ porphyrin per $\mathrm{g}$ faeces, wet weight with a sensitivity of $97 \%$ and a specificity of $96 \%$. These results indicate that the screening test is quite useful for detection of increased total faecal porphyrin concentration, but less useful in accurate measurement of increased total faecal porphyrin concentration.

\section{Introduction}

Recently we compared a first-line spectrophotometric screening test for urine porphyrins with a high-performance liquid chromatographic (HPLC) method for quantitative measurement of porphyrins. The screening test proved to be reliable. Sensitivity and specificity were $96 \%$ and $86 \%$, respectively (1). Porphyrin concentrations in urine specimens with a positive screening test are quantified using an HPLC method. With this method the individual porphyrin fractions can be investigated, which is necessary for identification of the kind of porphyria. To correctly identify the kind of porphyria, examination of faecal porphyrins is sometimes also required $(2-5)$. This is the case of establishing the diagnosis of erythropoietic protoporphyria, variegate porphyria and hereditary coproporphyria; then faecal porphyrins must also be differentiated by using the HPLC method.

Quantitative determination of faecal porphyrins and urine porphyrins are equally time consuming. Therefore a reliable screening test for faecal porphyrins would also be quite useful. Several methods have been criticized (2) but the method published by Lockwood et al. (6) is supposed to be useful because interference of faecal chlorophyll and carotenoid pigments is excluded $(6,7)$.
This method has been criticized by Pudek et al. (7) because measurement of the Soret band in extracts of normal stool specimens would be inaccurate. However, our preliminary results were encouraging. The method has been shown by others to perform well (3) but has not yet been compared with an HPLC method.

We used the screening procedure of Lockwood et al. (6) for extraction and measurement of faecal porphyrins followed by measurement with an HPLC method as has been described (8). We compared the sum of all faecal porphyrins (HPLC) with the results of the quantitative screening test.

\section{Materials and Methods \\ Screening test for increased faecal porphyrin concentration}

Quantitative measurement of faecal porphyrin concentration is performed as described by Lockwood et al. (6) and expressed per $g$ wet weight: $25-50 \mathrm{mg}$ faeces is collected and mixed (vortex) with $1 \mathrm{ml}$ conc. $\mathrm{HCl}(1.18 \mathrm{~kg} / \mathrm{l})$ until a homogenous suspension is obtained. After 5 minutes the suspension is mixed and $3 \mathrm{ml}$ diethyl ether is added. The suspension with the ether is thoroughly mixed until a homogenous emulsion is obtained. Then $3 \mathrm{ml}$ distilled water is added (within 10 minutes after mixing the faeces with the $\mathrm{HCl}$ ).

The emulsion is centrifuged at $2500 \mathrm{~g}$ for 10 minutes. 
From the lower aqueous layer approximately $3 \mathrm{ml}$ is transferred to a recording spectrophotometer cuvette and scanned from 390 to $425 \mathrm{~nm}$. Peak height is measured as the difference between the top of the peak and a tangent to the baseline curve drawn between two suitable points on each side of the porphyrin peak (e.g. 390 and $425 \mathrm{~nm}$ ) (6). The peak height (in units of absorbance) is multiplied by 14.850 , and divided by the weight in $\mathrm{mg}$ resulting in nmol porphyrin per $g$ faeces (wet weight). The coefficient of variation of the method is $1 \%(n=25)$, at the level of $65 \mathrm{nmol} / \mathrm{g}$ faeces.

Quantitative measurement of total faecal porphyrin concentration with HPLC

Our materials and procedures are in essence the same as those described extensively by Beukeveld et al. (8). In summary: we used a Biocompatible Binary LC Pump model 250 (Perkin Elmer Corp., Norwalk CT, USA). Samples were injected in a Rheodyne injector (Rheodyne Inc. Cotati CA, USA) with a $200 \mu l$ loop. Separation was performed on a $20 \mathrm{~cm}$ column $(5 \mu \mathrm{m}$ particles RP18, Brownlee Labs Inc., Santa Clara, CA, USA) preceded by a guard column filled with the same material. Separation of the porphyrins with a solvent gradient was performed exactly as described (8). The solvent gradient started with a low concentration of dimethylpyridine-phosphoric acid and ended with a high concentration of methanol both in an acetonitrile-acetone-water mixture.

Spectrofluorometric detection of the porphyrins was performed with a LS-5 spectrofluorometer (Perkin Elmer Corp., Norwalk, CT, USA): $\lambda$ excitation was $407 \mathrm{~nm}, \lambda$ emission was $620 \mathrm{~nm}$ with band widths of 10 and $20 \mathrm{~nm}$ respectively.

Reagents, eluents and stock standard solution of porphyrins have been described (8). Stock internal standard solution and working standards were the same as described. The coefficient of variation of the method is $6 \%(n=25)$.

\section{Specimens}

Samples were fresh or stored at $-25^{\circ} \mathrm{C}$ and protected from light by aluminum foil. Samples were processed and measurements were performed as soon as possible.

Dry weight - wet weight ratio of faeces

To facilitate comparison with the literature, we measured the dry weight ratio of 94 specimens by drying until weight remained constant. The mean ratio was 0.25 and the standard deviation was 0.06 .

\section{Patients}

We only used specimens from patients suspected of having porphyria $(n=164)$. The faecal porphyrin concentration as measured by HPLC was not increased in 100 patients. Clinical diagnosis in the remaining 64 patients was: porphyria cutanea tarda, $n=7$; variegate porphyria, $n=9$; acute intermittent porphyria; $n=1$; erythropoietic protoporphyria, $n=1$; hereditary coproporphyria, $\mathrm{n}=33$; none, $\mathrm{n}=13$.

\section{Reference value}

In 58 healthy persons aged 5 to 65 years (mean value 30 years) total faecal porphyrin concentration was calculated using the sum of copro-1-, copro-3-, deutero-, pempto-, meso- and protoporphyrin values as measured by HPLC:

Faecal porphyrin concentration higher than $45 \mathrm{nmol} / \mathrm{g}$ was considered increased. The mean concentration was $21 \mathrm{nmol} / \mathrm{g} ; \mathrm{SD}=12$ $\mathrm{nmol} / \mathrm{g}$; the range of the measured values was $5-49 \mathrm{nmol} / \mathrm{g}$.

\section{Statistical methods}

A receiver-operating characteristic (ROC) graph was calculated and constructed as described (9), although we refer to the $x$-axis as "false positive fraction". The area under the graph is estimated by weighing. Linear regression analysis is performed by the least squares method.

\section{Results}

Relation between the screening method and the HPLC method: no increase in faecal porphyrin concentration (HPLC method)

Figure 1 shows the relation between the screening test and the HPLC method. Several patients with clinical diagnosis porphyria cutanea tarda did not have an increased faecal total porphyrin concentration. The same applies to a patient with variegate porphyria. Though there is some scatter of the results, a correlation between both methods is clear. Regression analysis revealed: $\mathrm{y}=0.95 \mathrm{x}-1, \mathrm{y}=$ screening test, $\mathrm{x}=$ HPLC method; $r=0.79$.

Relation between the screening method and the HPLC method: increased faecal porphyrin concentration (HPLC method)

Figure $2 \mathrm{~A}$ illustrates a wide scatter of values. Visual inspection suggests that divergent regression curves can be calculated from the values of patients with hereditary coproporphyria and from the values measured in faeces of patients with variegate porphyria, porphyria cutanea tarda and erythropoietic protoporphyria.

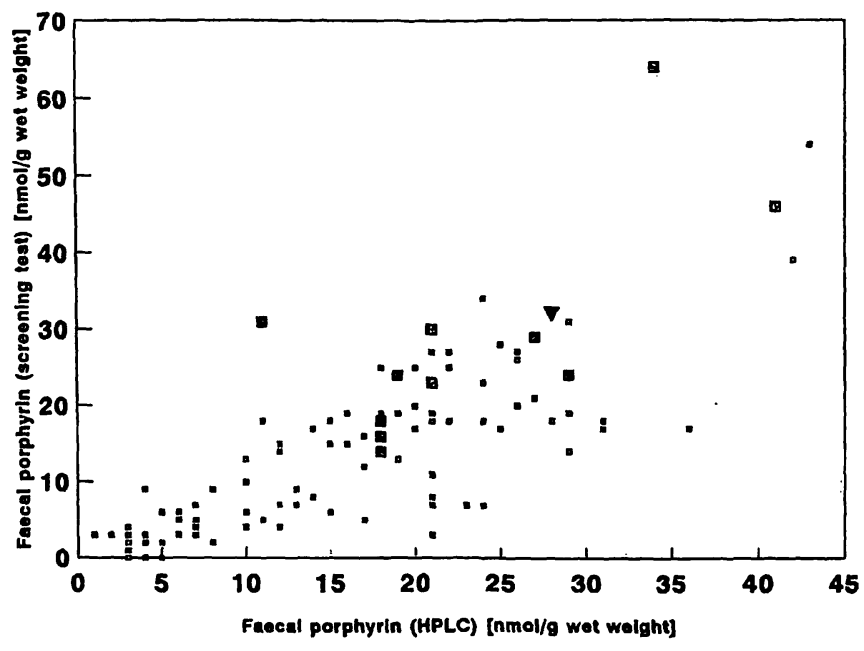

Fig. 1 Faecal porphyrin concentration: relation between the screening test and the HPLC method. Scattergram of faecal porphyrin concentration from patients suspected of porphyria without increased excretion, as measured by HPLC ( $\leqslant 45 \mathrm{nmol} / \mathrm{g}$ ).

porphyria cutanea tarda; $\nabla$ variegate porphyria; no diagnosis; $\mathrm{n}=100$. 


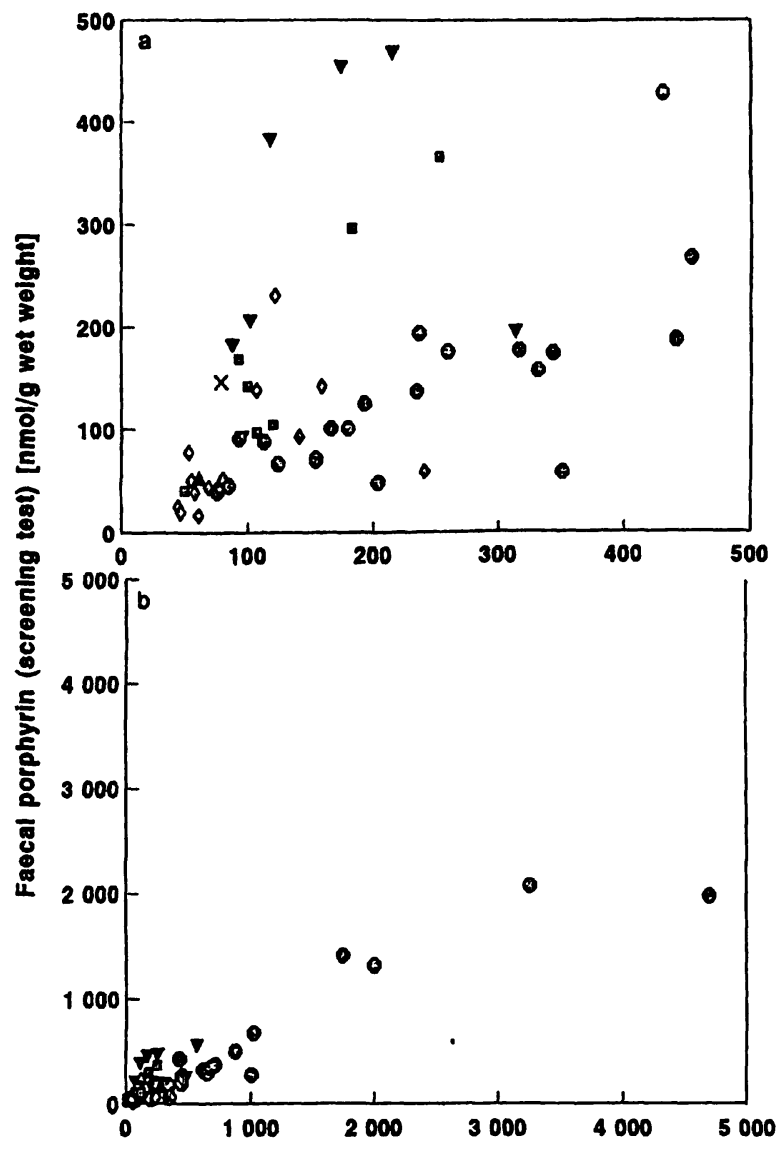

Faecal porphyrin (HPLC) [nmol/g wet weight]

Fig. 2a, b Faecal porphyrin concentration: relation between the screening test and the HPLC method.

a: Scattergram of faecal porphyrin concentration from all patients suspected of porphyria with increased concentration from 45 up to $500 \mathrm{nmol} / \mathrm{g}$, as measured by HPLC; $\mathrm{n}=51$.

b: Scattergram of faecal porphyrin concentration from all patients suspected of porphyria with increased concentration from 45 up to $5000 \mathrm{nmol} / \mathrm{g}$, as measured by HPLC; $\mathrm{n}=64$.

$a$ and $b: \mathbf{D}$ porphyria cutanea tarda; $\nabla$ variegate porphyria; $\bullet$ hereditary coproporphyria; $\Delta$ acute intermittent porphyria; $\mathbf{x}$ erythropoietic protoporphyria; no diagnosis.

Regression analysis of all values revealed:

$y=0.49 x+61, y=$ screening test, $x=$ HPLC method; $r=0.48$.

Figure $2 b$ does not illustrate $a$ wide scatter of values.

The values depicted in figure $2 \mathrm{a}$ are incorporated in figure $2 b$.

Regression analysis revealed:

$y=0.50 x+65, y=$ screening test, $x=$ HPLC method; $r=0.94$.

\section{Receiver-operating characteristic (ROC) plot}

From all 164 pairs of values, a ROC plot was constructed. In figure 3 the false positive and true positive values are illustrated from seven decision threshold values ranging from 15 to $65 \mathrm{nmol} / \mathrm{g}$ (as measured using the screening method). All values measured by HPLC $>45 \mathrm{nmol} / \mathrm{g}$ are increased porphyrin concentrations. The area under the ROC curve as measured by weighing is estimated to be more than 0.98 .

\section{Discussion}

The screening procedure for faecal porphyrins as described by Lockwood et al. (6) is quite similar to the method for porphyrins in the urine examined by us (1) and by others (3) previously. The main difference is extraction of carotenoïds and chlorophyll from the faecal suspension prior to spectrophotometry of the acid layer. The screening method of Lockwood et al. (6) seems to perform quite well (3) and it was convenient for us to investigate this method.

For evaluation of the screening method, a quantitative HPLC procedure is necessary. We used the HPLC method of Beukeveld et al. (8) and measured reference values for total faecal porphyrins in our own laboratory. Our range was $5-49 \mathrm{nmol} / \mathrm{g}$ wet weight $(\overline{\mathrm{x}}=21$ $\mathrm{nmol} / \mathrm{g}, \mathrm{SD}=12 \mathrm{nmol} / \mathrm{g}$ ) which hardly differed from the range published by Beukeveld et al. (8): 2-57 $\mathrm{nmol} / \mathrm{g}$ wet weight. The upper limit of our reference interval is $45 \mathrm{nmol} / \mathrm{g}$. Often faecal porphyrin concentrations are expressed per $g$ dry weight. It has been shown that values per $g$ wet weight have the same diagnostic value provided of course that reference values are expressed in the same way (10). In that paper the percentage dry weight to wet weight was $25.8 \%$ ( $\mathrm{SD}=8.5 \%$, $\mathrm{n}=213$ ). This mean value is the same as our value (see section Materials and Methods). Therefore we can compare our reference value with those who expressed it per

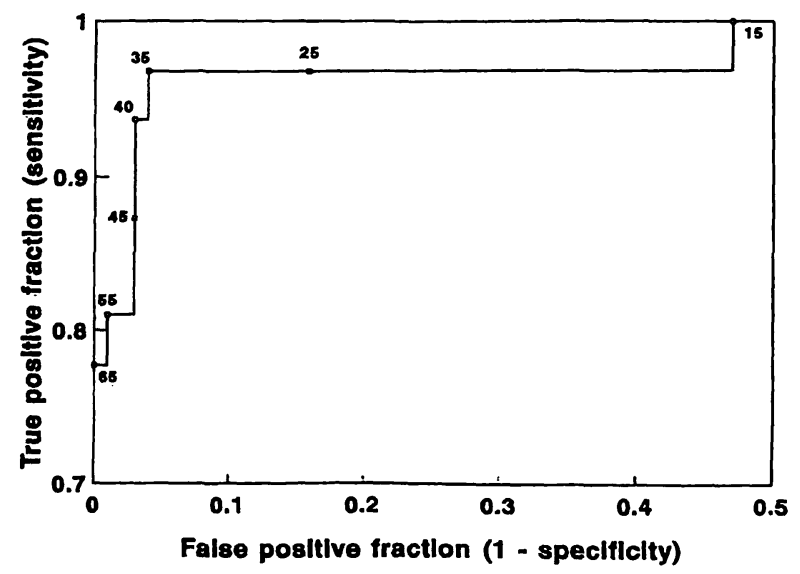

Fig. 3 ROC plot of the number of samples measured with the screening test showing normal and increased faecal porphyrin concentration as compared to the number of samples selected with the HPLC method ( $n=164$ ). Values in the graph indicate the cut-off values for increased faecal porphyrin concentration in $\mathrm{nmol} / \mathrm{g}$ as measured with the screening test. The cut-off value in the HPLC method is $45 \mathrm{nmol} / \mathrm{g}$. 
g dry weight. The reference value $<200 \mathrm{nmol} / \mathrm{g}$ dry weight found by others $(2,3,6,11)$ is almost identical to our value: $\leq 45 \mathrm{nmol} / \mathrm{g}$ wet weight (which is approximately $180 \mathrm{nmol} / \mathrm{g}$ dry weight). Therefore our comparison of the screening method with our HPLC method possibly applies to other methods as well.

In figure 1 some scatter of values is apparent. However, there is a clear correlation between both methods. Contrary to our results with the screening method for porphyrins in urine (1), this method for faecal extracts always measures a porphyrin concentration if a concentration higher than $5 \mathrm{nmol} / \mathrm{g}$ wet weight is found by HPLC. In several cases the faecal extract of known patients with porphyria cutanea tarda did not show increased porphyrin concentration. These faecal samples may have been collected from patients in a period of clinical remission (2). The same holds for the case of variegate porphyria (4).

In figure $2 \mathrm{a} / \mathrm{b}$ all patients with increased faecal porphyrin concentration are shown. In figure $2 b$ the relation between both methods is not very different from the one calculated in figure 2a. However, visual inspection of figure $2 \mathrm{a}$ reveals a wide scatter of values. Patients with variegate porphyria, porphyria cutanea tarda and one patient with erythropoietic protoporphyria tend to show a different regression than patients with hereditary coproporphyria. Absorbance at the same concentration of porphyrins as measured by HPLC for specimens from the latter group of patients seemed less than for the other groups of patients.

Patients with hereditary coproporphyria excrete relatively more coproporphyrins in faeces whereas the other

\section{References}

1. Zuijderhoudt FMJ, Dorresteijn-de Bok J, te Velde K. Evaluation of a first-line spectrophotometric screening test for increased urine porphyrin excretion. Ann Clin Biochem 1995; 32:186-9.

2. Elder GH, Smith SG, Jane Smyth S. Laboratory investigation of the porphyrias. Ann Clin Biochem 1990; 27:395-412.

3. Deacon AC. Performance of screening tests for porphyria. Ann Clin Biochem 1988; 25:392-7.

4. Hindmarsh JP. The porphyrias: recent advances. Clin Chem 1986; 32:1255-63.

5. Kushner JP. Laboratory diagnosis of the porphyrias. New Eng J Med 1991; 324:1432-4.

6. Lockwood WH, Poulos V, Rossi E, Curnow DH. Rapid procedure for fecal prophyrin assay. Clin Chem 1985; 31:1163-7.

7. Pudek MR, Schreiber WE, Jamani A. Quantative fluorometric screening test for fecal porphyrins. Clin Chem 1991; 37:826-31.

8. Beukeveld GJJ, Wolthers BG, van Saene JMM, de Haan THIJ, de Ruyter-Buitenhuis LW, van Saene RHF. Patterns of porphy- groups of patients excrete relatively more protoporphyrin and protoporphyrin derived porphyrins $(2,4)$.

We wondered whether the ratio of copro- and protoporphyrin in these fractions influenced the absorbance in the Soret band producing the results shown in figure $2 a$. If the molar absorbance of coproporphyrin in the faiecal extract is less than that for protoporphyrin then some explanation exists for our observation. However the molar absorption coefficients published by Lockwood et al. (6) did not confirm this. We have no explanation for the scatter of the values in figure 2a. The correlation of our reference values (HPLC method) with those from literature suggests that the HPLC method is reasonably accurate; precision is satisfactory too, coefficients of variation of the HPLC method and the screening method are respectively $6 \%$ and $1 \%$. The sensitivity and specificity of the screening test (97\% and $96 \%$, respectively) are very good at a cut-off value of $35 \mathrm{nmol} / \mathrm{g}$ (fig. 3). Therefore we chose $35 \mathrm{nmol} / \mathrm{g}$ as the upper reference value of the screening test. In figure 1 some values that were increased as measured by the screening test will successively be classified as normal with the HPLC method. The area under the ROC plot is high, 0.98 , illustrating that this screening test for increased faecal porphyrin concentration is also quite useful and even superior to the comparable screening test for increased urine porphyrin excretion (1). The method can not be used for accurate measurement of increased total faecal porphy: rin concentration.

\section{Acknowledgements}

The authors thank Mr. $\mathscr{W}$. Kluitenberg for statistical calculations and Mrs. Rook for assistance in preparing the manuscript. rin excretion in feces as determined by liquid chromatography; reference values and the effect of flora suppression. Clin Chem 1987; 33:2164-70.

9. Zweig $\mathrm{MH}$, Campbell G. Receiver-operating characteristic (ROC) plots: a fundamental evaluation tool in clinical medicine. Clin Chem 1993; 39:561-77.

10. Deacon AC. Fecal porphyrin screening. Clin Chem 1990; 36:1383.

11. Blake D, McManus J, Cronin V, Ratnaike S. Fecal coproporphyrin isomers in hereditary coproporphyria. Clin Chem 1992; 38:96-100.

Dr. F. M. J. Zuijderhoudt

Deventer Ziekenhuis

Postbus 5001

NL-7400 GC Deventer

The Netherlands 